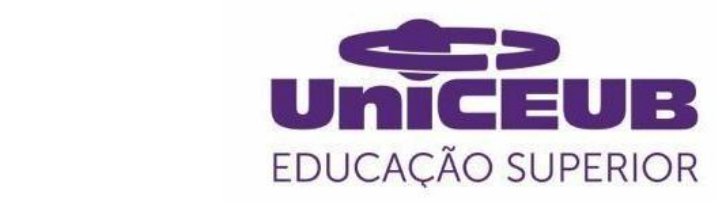

CENTRO UNIVERSITÁRIO DE BRASÍLIA- UnICEUB PROGRAMA DE INICIAÇÃO CIENTÍFICA

ANA LUIZA ALVES PANTA VASCONCELOS

RAIANNY PIRES LÔBO

AVALIAÇÃO DA TRANSFERÊNCIA PASSIVA DE ANTICORPOS PELA INGESTÃO DE COLOSTRO EM EQUINOS NO DISTRITO FEDERAL

BRASÍLIA 


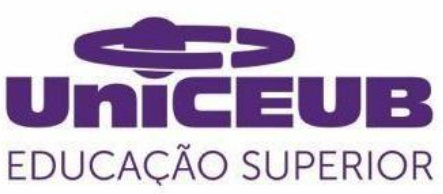

\author{
ANA LUIZA ALVES PANTA VASCONCELOS \\ RAIANNY PIRES LÔBO
}

\title{
AVALIAÇÃO DA TRANSFERÊNCIA PASSIVA DE ANTICORPOS PELA INGESTÃO DE COLOSTRO EM EQUINOS NO DISTRITO FEDERAL
}

Relatório final de pesquisa de Iniciação Científica apresentado à Assessoria de PósGraduação e Pesquisa.

Orientação: Professor Dr. Carlos Henrique Camara Saquetti

BRASÍLIA 


\section{RESUMO}

No Brasil, o comércio que envolve a criação e utilização do cavalo ocupa uma posição de destaque, contando com um rebanho de 5,8 milhões de cabeças e mobilizando ao ano $R \$ 16$ bilhões (MAPA, 2016). Neste contexto de importância da equideocultura, crescentes estudos científicos alertam para melhorias técnicas na qualidade produtiva da criação dos equinos, em especial da vida fetal até o nascimento. Isso porque $50 \%$ das perdas de um criatório e redução de produtividade estão relacionadas às Falhas de Transferência de Imunidade Passiva (FTIP), evento concentrado nas primeiras horas de vida dos neonatos e sua adequada imunização via colostro materno (COHEN, 1994; GOMES et al., 2010). As FTIP elevam a ocorrência de algumas enfermidades como enterites, pneumonias bacterianas, septicemia e artrite séptica, caracterizadas por acometerem esses animais em suas primeiras três semanas de vida, causando diminuição na taxa de crescimento, perda de rendimento, podendo levar a óbito e gerar grandes perdas econômicas ao criador, considerando também os altos gastos com tratamento (NATH, ANDERSON, SAVAGE \&amp; MCKINNON, 2010). Para realização do experimento, foi coletada uma amostra de sangue de cada égua genitora, totalizando dez éguas, e amostras de seus respectivos potros logo após o nascimento, às 12, 24 horas, 15 e 30 dias de vida e dosados os níveis de Proteína Totais e Frações. Não foram observados casos de FTPI, dos potros analisados no experimento, dois apresentaram níveis elevados de proteínas plasmáticas totais e globulinas logo após o nascimento, indicando exposição intra-uterina a antígenos. Aos 30 dias de vida foi observado um aumento dos níveis de proteínas totais e globulinas nos potros, indicando uma produção endógena de imunoglobulinas maior do que o catabolismo de imunoglobulinas adquiridas. Também não foi observada relação entre os níveis de proteínas plasmáticas totais e globulinas das éguas genitoras e de seus respectivos potros após a ingestão do colostro. Portanto, verificou-se que a oferta de colostro em tempo hábil corrobora para um melhor aproveitamento do neonato, uma vez que este foi suficiente para prover a imunidade necessária, porém, esta imunidade não se prolongou, indicado pela elevação de globulinas endógenas aos 30 dias. Isso pode se dar pela qualidade do colostro, que não foi suficiente para suprimir a imunidade endógena do potro. Dessa forma se faz importante a análise do colostro em estudos futuros, definindo a relação de sua qualidade com os níveis séricos de imunoglobulinas maternas e quantificando quanto dessas imunoglobulinas efetivamente chega ao neonato.

Palavras-Chave: Imunidade. Potros. Imunoglobulinas 
SUMÁRIO

INTRODUÇÃO

FUNDAMENTAÇÃO TEÓRICA

MÉTODO 9

RESULTADOS E DISCUSSÃO

CONSIDERAÇÕES FINAIS

REFERÊNCIAS 


\section{INTRODUÇÃO}

No Brasil, o comércio que envolve a criação e utilização do cavalo ocupa uma posição de destaque, contando com um rebanho de 5,8 milhões de cabeças e mobilizando ao ano $\mathrm{R} \$$ 16 bilhões (MAPA, 2016). Apesar de pouco considerada economicamente, um interessante levantamento de Lima e colaboradores (2006) revelou que o crescente setor gera 640 mil empregos diretos e 200.000 indiretos, mais que a presente indústria automobilística. Dentre as várias atividades, o equino está incluso em trabalho, nas funções de sela, carga e tração, e desde a metade do século XX vem se destacando em atividades esportivas e entretenimento, bem como na área da saúde, com seu uso no tratamento de portadores de dificuldades cognitivas, psicomotoras e sócio afetivas.

Neste contexto de importância da equideocultura, crescentes estudos científicos alertam para melhorias técnicas na qualidade produtiva da criação dos equinos, em especial da vida fetal até o nascimento. Isso porque $50 \%$ das perdas de um criatório e redução de produtividade estão relacionadas com as Falhas de Transferência de Imunidade Passiva (FTIP), evento concentrado nas primeiras horas de vida dos neonatos e sua adequada imunização via colostro materno (COHEN, 1994; GOMES et al., 2010).

As FTIP elevam a ocorrência de algumas enfermidades como enterites, pneumonias bacterianas, septicemia e artrite séptica, caracterizadas por acometerem esses animais em suas primeiras três semanas de vida, causando diminuição na taxa de crescimento, perda de rendimento, podendo levar a óbito e gerar grandes perdas econômicas ao criador, considerando também os altos gastos com tratamento (NATH, ANDERSON, SAVAGE \&amp; MCKINNON, 2010).

A importância da transferência passiva pelo colostro é explicada fisiologicamente. Nas éguas, a placenta do tipo epiteliocorial, sem contato sanguíneo materno-fetal, o que impossibilita a passagem de alguns nutrientes, dentre eles proteínas e anticorpos. Assim, a imunização provida pelo colostro, em especial nas primeiras 12 horas de vida, é determinante tanto para a sobrevivência neonatal quanto para a qualidade de vida do potro jovem (KOTERBA; DRUMMOND; KOSCH, 1990). As causas de ocorrência de FTIP são variadas, podem ser devido a não ingestão durante as primeiras 12 horas depois do parto, a falha de absorção intestinal por parte do potro e concentrações inadequadas Imunoglobulina G (IgG) do colostro materno (KOTERBA; DRUMMOND; KOSCH, 1990) 
Com exceção da incapacidade inata de absorção intestinal do neonato, as demais causas são passíveis de atuação técnica, tanto preventiva quanto clínica. Historicamente utilizado em diversas espécies, a estimulação imunológica vacinal da égua no período gestacional é uma atuação preventiva na qualidade imunológica neonatal. Também a determinação de níveis séricos de IgG no neonato durante as primeiras horas de vida possibilitam uma intervenção clínica precoce, como a administração oral ou endovenosa de anticorpos (SARDINHA et al, 2017).

Apesar de haver muitos artigos acerca dessa afecção em potros neonatos, essa é uma temática muito negligenciada pelos criadores de equinos que, na maioria das vezes, não adotam métodos de prevenção e acabam perdendo seus animais. Em relação aos animais do Distrito Federal, é de suma importância o estudo dos principais antígenos da localidade, para que se obtenha os anticorpos necessários, conferindo bom estado de saúde ao potro.

O objetivo do presente estudo foi avaliar a transferência de imunoglobulinas via colostro no Distrito Federal, por meio da avaliação da concentração de proteínas totais e suas frações, comparando com os níveis das éguas genitoras, possibilitando acompanhar os períodos de aumento e redução dos níveis de imunoglobulinas e diagnosticar possíveis casos de FTPI. 


\section{FUNDAMENTAÇÃO TEÓRICA}

Os equinos neonatos nascem hipo ou agamaglobulinêmicos devido a placenta de natureza epiteliocorial difusa das éguas, que possuem seis camadas de tecido entre a circulação materna e fetal. Esses tecidos compreendem o endotélio vascular materno, o tecido conjuntivo uterino, o epitélio uterino, o epitélio coriônico, o tecido conjuntivo fetal e o endotélio vascular fetal, que formam uma barreira que impede a transferência transplacentária de imunoglobulinas (JEFFCOTT, 1974; MCGUIRE et al., 1975; KOTERBA et al., 1990; TIZARD, 2002).

Nessa espécie a transferência de imunidade passiva ocorre via colostro, que é uma forma de leite amarelado que começa a ser produzido nas duas últimas semanas da gestação e é conhecido como "primeiro leite". O colostro possui um grande valor nutricional, sendo rico, principalmente, em imunoglobulinas, que são moléculas proteicas, selecionadas a partir do plasma sanguíneo das éguas, além de ser fonte de água, proteínas, carboidratos, lipídios, vitaminas, minerais e enzimas importantes para o desenvolvimento do animal (UNANIAN, 1994).

Nas primeiras 24 horas de vida sua eficiência é mais elevada, sendo que o melhor momento de aproveitamento total deste colostro é até 12 horas após o nascimento, principalmente nas primeiras 2 a 6 horas, em que ocorre o pico de absorção da mucosa intestinal. Uma vez que é ingerido, há a absorção de imunoglobulinas não seletivamente por pinocitose ao longo do intestino, os enterócitos acumulam gotículas de colostro em seu interior, transferindo-as para vacúolos e descarregando-as em vasos linfáticos e então na circulação sanguínea. Esse processo ocorre principalmente no íleo (BLACKMER et al., 2002; RAIDAL et al., 2005). A capacidade de absorção diminui de 18 a 24 horas pós-parto, pois as células epiteliais intestinais são substituídas por células maduras, incapazes de realizar pinocitose, ao mesmo tempo em que ocorrem mudanças na composição da secreção láctea, como por exemplo, o declínio na concentração de imunoglobulinas, caracterizando a substituição do colostro pelo leite (UNANIAN, 1994). A maioria das imunoglobulinas no colostro equino é $\lg G$, com menores concentrações de $\lg A$ e $\operatorname{lgM}$, por isso sua avaliação é importante para o diagnóstico de possíveis casos de falha na transferência passiva de imunidade (FTIP), a fim de iniciar um tratamento precoce e bem-sucedido (TIZARD, 2004). 
Fatores como raça, estágio de lactação, aporte nutricional da fêmea e condições ambientais afetam as características físico químicas do colostro (VILAR et al, 2008).

O colostro também provém ao neonato agentes imunomoduladores, citocinas, fatores de crescimento, hormônios, linfócitos, macrófagos, neutrófilos e células epiteliais (SELLON et al., 2009). A secreção de proteínas totais e, portanto, de IgG, aumenta nos últimos 10 dias de gestação, atingindo um pico no momento do parto e decrescendo em seguida. (ZOU et al., 1997). A maioria das éguas produz de 1,8 a $2,8 \mathrm{~L}$ de colostro por cada parição (KOHN et al.,1989). Em éguas multíparas, ou seja, que já pariram mais de uma vez, a taxa de secreção de colostro é, em média, $300 \mathrm{~mL} / \mathrm{h}$ e o volume total produzido varia entre 2 e $5 \mathrm{~L}$ (LAVOIE et al., 1989).

O pico de IgG sérico no potro, proveniente do colostro, é atingido às 18 horas pósparto, quando a concentração sérica é semelhante à do soro da mãe. Os anticorpos passivos declinam gradualmente até estarem completamente ausentes aos 5 meses de idade. Imunoglobulinas endógenas são encontradas pela primeira vez com 2 semanas de idade, não sendo observadas concentrações séricas consideráveis até os 2 meses de idade. As concentrações aumentam gradativamente até atingir o nível dos adultos aos 5 meses (JEFFCOTT, 1974; MCGUIRE et al., 1977). Por outro lado, quando se verifica a ingestão de colostro, são identificadas Imunoglobulinas endógenas apenas às 4 semanas de idade, ou seja, o início da imunidade ativa mais tardio devido a supressão do sistema imune pelos anticorpos de origem materna (JEFFCOTT, 1974).

A maior parte do sistema imune do feto se desenvolve durante a gestação, dessa forma, o potro nasce imunocompetente, produzindo anticorpos a medida em que é exposto a novos antígenos no ambiente. (GIGUÈRE \& POLKES, 2005). A concentração sérica de imunoglobulinas ao nascimento é normalmente baixa e reflete o grau de estimulação antigênica que o feto sofreu no útero, ambiente praticamente estéril (TIZARD, 2004). Por isso, nos primeiros 1 a 2 meses de vida a proteção dos potros se dá pelos anticorpos colostrais, que diminuem à medida em que são expostos a antígenos e produzem anticorpos endógenos. Portanto, em condições ideais, o potro está sempre imunologicamente protegido (REED et al., 2004).

Levando em conta a concentração sérica no potro, o teor de IgG considerado adequado após a transferência varia de 400 a $800 \mathrm{mg} / \mathrm{dL}$ de IgG. Valores abaixo de $200 \mathrm{mg} / \mathrm{dL}$ são considerados FTIP completa, e de 200 a 400 ou 800 mg/dL são considerados FTIP parcial. Essa 
variação do valor adequado ocorre em decorrência do ambiente, em ambientes limpos, sem muitos patógenos virulentos, $400 \mathrm{mg} / \mathrm{dL}$ é considerado adequado, porém em ambientes em que estão em contato com uma grande quantidade de patógenos ou apresentam sinais de infecção, é inadequado (SMITH, 2002). Alguns autores sugerem que ocorre FTIP em potros quando a concentração sérica de PT for menor que $4.800 \mathrm{mg} / \mathrm{dL}$ (METZGER et al. 2006) ou globulina total sérica menor que $2.230 \mathrm{mg} / \mathrm{dL}$ (HURCOMBE et al. 2012) A prevalência reportada de falha, total ou parcial, na transferência passiva varia de $3 \%$ a $37 \%$, dependendo do ambiente em que o neonato está inserido (REED et al., 2004).

A FTIP foi considerada a síndrome de imunodeficiência mais dispendiosa e prevalente nos equinos (BAIRD et al., 1987). Entre as causas dessa há fatores ligados à falha na produção de colostro, ou colostro de qualidade reduzida, que pode acometer principalmente fêmeas primíparas por deficiência na migração de Ig para as glândulas mamárias (CHUCRI et al., 2010). Pode ocorrer lactação prematura, em que há secreção e excreção de colostro nos dias que precedem o parto, reduzindo a concentração de anticorpos disponíveis para o neonato. Esta condição está geralmente relacionada à placentite ou separação prematura da placenta. (GIGUÈRE \& POLKES, 2005). Há também fatores ligados à falha na ingestão de colostro, como nos casos de rejeição do potro pela égua, quando há fraqueza do mesmo ou desenvolvimento tardio do reflexo de sucção. Dessa forma, o neonato ingere quantidades insuficientes de colostro ou não o ingere. (PERRYMAN et al., 1980). E, por fim, há fatores relacionados à falha na absorção do colostro, quando os potros demoram 24 horas ou mais para ingerir o colostro, comprometendo a absorção intestinal, uma vez que a capacidade intestinal de absorção de proteínas já cessou, quando há baixa concentração de IgG no colostro, ou na presença de alguma anomalia na absorção intestinal. (MUNROE \& STONEHAM, 2011)

Independentemente de haver uma boa criação, cerca de $28 \%$ das éguas são produtoras de colostro de má qualidade e $25 \%$ dos potros não são capazes de absorver imunoglobulinas de forma satisfatória. Dessa forma, realizar a avaliação da qualidade do colostro e da taxa de transferência passiva de imunidade são práticas sempre indicadas (TIZARD, 2014).

Uma vez diagnosticada a FTIP, o tratamento a ser adotado depende do tempo decorrido até o diagnóstico, ao estado geral de saúde do potro, se há manifestação de algum sinal clínico ou indicação de septicemia em exames hematológicos e à qualidade do colostro ingerido (TIZARD, 2004; CRISMAN \& SCARRATT, 2008). Quando diagnosticada precocemente, nas primeiras 6 horas de vida do potro, recomenda-se a administração via oral de colostro. 
Deve-se fornecer de 1 a 2 litros do mesmo, de acordo com sua qualidade (quantidade de IgG) e o peso do potro, administrando de 300 a $500 \mathrm{~mL}$ com intervalos de 1 a 2 horas (MUNROE \& STONEHAM, 2011). A concentração de IgG, o índice de refração ou a densidade do colostro da égua doadora devem ser avaliados antes de sua utilização, a fim de certificar a qualidade do mesmo (STONEHAM, 1991; ACWORTH, 2003).

Até 4 horas após o nascimento, a administração oral de plasma hiperimune via sonda nasogástrica pode ser adotada como alternativa ao colostro. Entretanto, nesse as imunoglobulinas encontram-se mais diluídas do que no colostro, sendo necessário administrar cerca de cinco vezes a quantidade recomendada de colostro para atingir os mesmos resultados (MUNROE \& STONEHAM, 2011).

Uma vez que o diagnóstico é realizado após o período de efetiva absorção intestinal e o nível sérico de IgG se encontra abaixo do mínimo necessário, deve ser feita a transfusão sanguínea de plasma. Este deve ser fornecido em quantidade suficiente para que a concentração de IgG sérica seja superior a 800 mg/dL (SELLON, 2000; MUNROE \& STONEHAM, 2011). O plasma a ser utilizado deve ser coletado assepticamente de um doador testado para doenças transmissíveis, conter pelo menos $70 \mathrm{~g} / \mathrm{L}$ de Proteínas Totais (TYLER-MCGOWAN et al., 1997) e concentração de IgG acima de 15 g/L. As concentrações de IgG devem ser dosadas de 18 a 24 horas após a transfusão a fim de avaliar seu efeito. Deve-se repetir o procedimento até que os níveis de IgG estejam adequados (STONEHAM, 1991; MUNROE \& STONEHAM, 2011). Em casos de FTIP e septicemia são utilizados antibióticos de largo espectro (CRISMAN \& SCARRATT, 2008).

\section{MÉTODO}

O experimento foi conduzido na Fazenda Dois Corações, localizada nas coordenadas 15028 '36.5" Sul, 47o 59' 52.5" Oeste, Sobradinho, Brasília-DF, no período de novembro de 2019 a março de 2020. Na propriedade o foco é a reprodução e comercialização de equinos da raça Mangalarga Marchador, onde uma matriz é inseminada, gera um embrião e este é transferido para ser gerado em uma égua receptora. Todas as éguas são submetidas a um protocolo vacinal, contra encefalomielite viral equina leste e oeste, tétano e influenza equina I e II (tríplice viral ), Herpesvírus Equino e Leptospirose. E mantidas em piquetes de capim 
Tifton, a alimentação é complementada com silagem, além de água proveniente de poço outorgado ad libitum.

Foi possível acompanhar o final da gestação de 10 éguas e o nascimento de seus respectivos potros, onde no dia 0 (dia do nascimento) foi coletada uma amostra de sangue da mãe, e do potro antes do mesmo ingerir o colostro, sendo que a ingestão deste foi acompanhada, seguindo com coletas de sangue do potro após $12 \mathrm{~h}, 24 \mathrm{~h}, 15$ e 30 dias do nascimento, a fim de detectar os níveis séricos de proteínas totais e suas frações no soro sanguíneo. Com isso possibilitou-se observar se houve transferência de anticorpos da égua para o potro e a relação da quantidade de anticorpos da mãe com a taxa de transferência.

Todas as amostras de sangue do experimento foram coletadas por venopunção jugular, utilizando Vacutainer e tubos para coleta a vácuo sem anticoagulante após assepsia local com álcool iodado. Para isso foi necessário realizar contenção das éguas com o auxílio de cabresto e o dos potros por meio da contenção física em pé abraçando-o pela frente, no peito e pela garupa, na base da cauda, impedindo que ele se deslocasse para frente ou para trás.

As amostras de sangue foram identificadas com o nome da mãe e a data da coleta, e transportadas em caixas de isopor com barras de gelo reutilizável ao laboratório Lab Care, localizado na Asa Sul, CLS 412, Loja 27, Brasília-DF. Foram realizados o exame de Proteínas Totais e Frações, sendo as frações compostas por Albumina e Globulinas, nestas estão inseridas as Imunoglobulinas, moléculas proteicas que foram quantificadas para prover os dados que serão apresentados neste relatório. Quando não houve possibilidade de transporte das amostras no dia da coleta, foi realizada a separação do soro sanguíneo, por meio de centrifugação, e este foi mantido congelado até que pudesse ser transportado. Os dados obtidos foram registrados ao longo do experimento e submetidos à análise estatística.

\section{RESULTADOS E DISCUSSÃO}

Nos dez potros utilizados no presente estudo não foram observados casos de Falha de Transferência de Imunidade Passiva, uma vez que após a ingestão do colostro os níveis de 
proteínas plasmáticas totais se encontravam acima de $4.800 \mathrm{mg} / \mathrm{dL}$ e globulina total sérica acima de $2.230 \mathrm{mg} / \mathrm{dL}$ em todos os animais, que são os valores mínimos para se considerar uma transferência adequada de acordo com Metzger e Hurcombe et.al. Para essa análise foram utilizados os dados de 24 horas após o nascimento dos potros (T24), pois o pico de imunoglobulinas séricas é atingido às 18 horas pós-parto (MCGUIRE et al., 1977). Essa porcentagem não condiz com a prevalência reportada de falha, total ou parcial, na transferência passiva segundo Reed et. al.(2004), que varia de $3 \%$ a 37\%, dependendo do ambiente em que o neonato está inserido, possivelmente pela imunização adequada das éguas, colostragem correta ou número reduzido de animais utilizados no experimento.

Dos dez animais do estudo, foi possível analisar amostras de oito potros coletadas logo após o nascimento (TO), visto que, devido a condições de parto dificultoso, preferiu-se não realizar coletas de sangue. Seis desses nasceram hipogamaglobulêmicos (75\%), entretanto, ao contrário do discorrido por Hafez e Hafez (2004) e Acworth (2003), dois potros (25\%) nasceram com níveis elevados de proteínas plasmáticas totais e globulinas, animal de número 3 e 8 como mostra o gráfico 1. Segundo Cook et. al. (2001) e LeBlank (1990), podem ser detectadas quantidades significativas de imunoglobulinas de origem endógena em potros neonatos antes da ingestão de colostro, estando relacionadas à exposição intra-uterina a antígenos após os 180 dias de gestação, que é a partir de quando os linfócitos B fetais são capazes de produzir e secretar essas imunoglobulinas, em especial o IgM e o IgG.

Gráfico 1. Níveis de proteína total, albumina e globulina do potros, antes da ingestão do colostro 


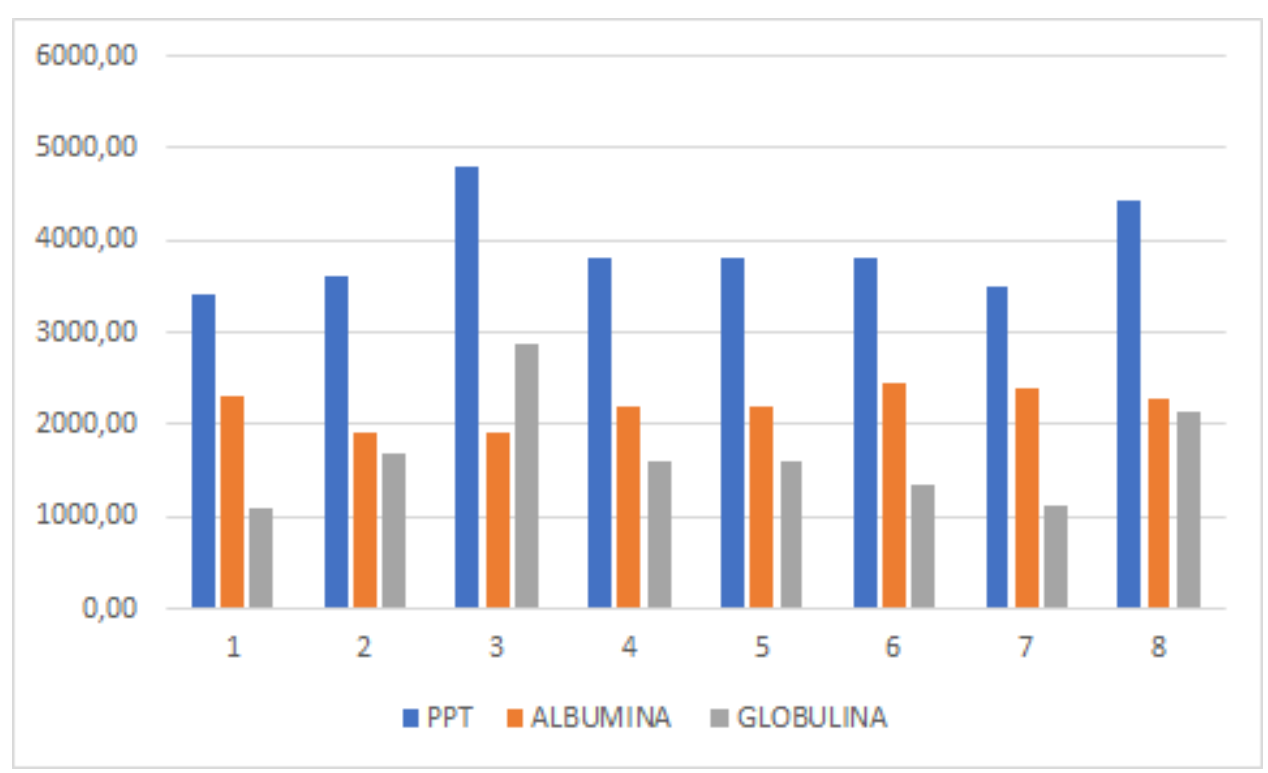

Fonte: arquivo próprio

Como observado no gráfico 2, a partir de 12 horas (T12) até 24 horas do nascimento (T24) houve redução dos níveis de albumina e elevação dos níveis de globulina, bem como das proteínas plasmáticas totais (PPT), indicando o sucesso na transferência passiva de imunidade. Fisiologicamente, de 2 a 30 dias ocorre um pico de IgG sérica adquirida de forma passiva até às 48 horas de vida, isso equivale a $80 \%$ da concentração média observada em animais adultos, seguida de uma fase de catabolismo até os 30 dias, em que há uma diminuição gradativa dos níveis séricos de proteínas (SCOTONI; MACHADO NETO, 1991). Observa-se então uma estabilização que reflete a produção endógena de imunoglobulinas pelo neonato, maior que o catabolismo verificado no período anterior (VALENTE et al., 2003). No experimento foi observado que aos 30 dias já havia uma produção endógena maior do que o catabolismo de imunoglobulinas adquiridas, representado pelo aumento nos níveis de PPT e globulinas. Isso pode se dar pela qualidade do colostro, pois segundo Jeffcott (1974), quando se verifica a ingestão de colostro de qualidade elevada, ocorre o início da imunidade ativa mais tardio devido a supressão do sistema imune pelos anticorpos de origem materna, o que não foi observado.

Gráfico 2. Níveis proteína total, albumina e globulina (mg/dl), antes do potro ingerir o colostro, $12 \mathrm{~h}, 24 \mathrm{~h}, 15$ e 30 dias depois 


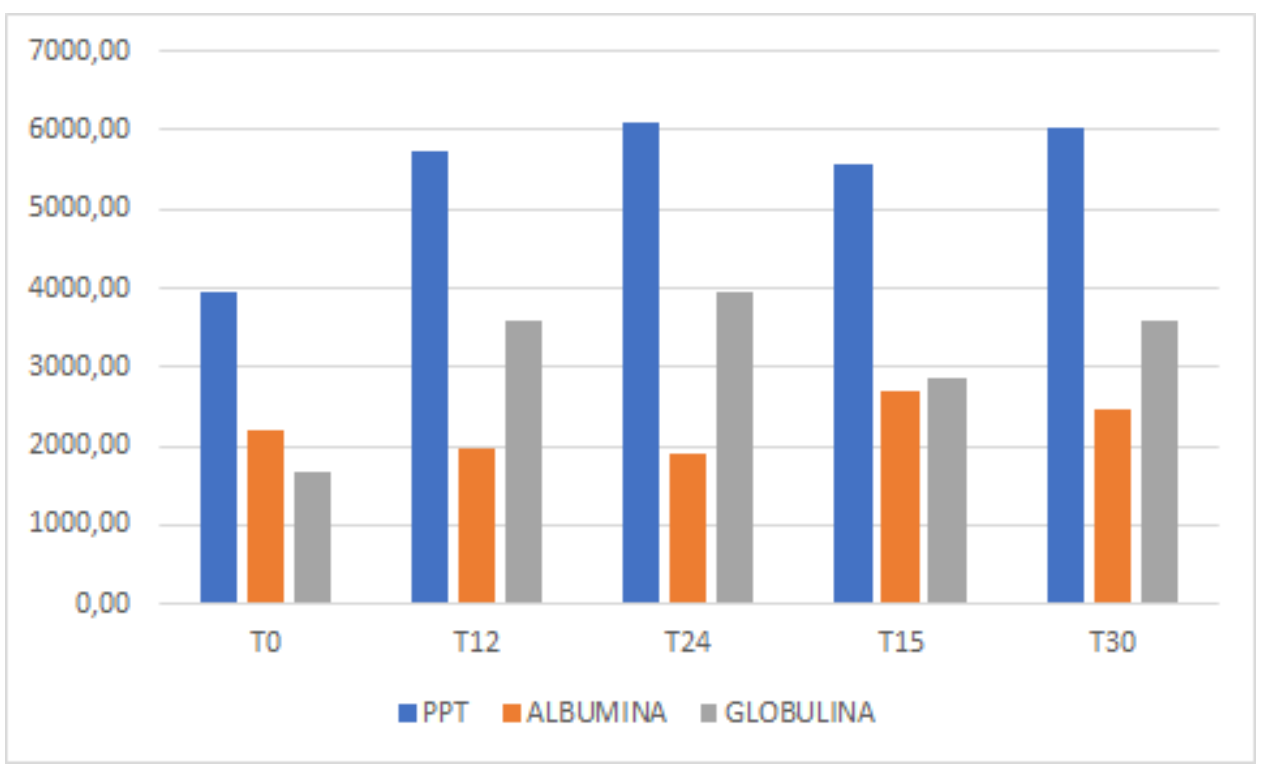

Fonte: arquivo próprio

Imunoglobulinas endógenas são encontradas pela primeira vez com 2 semanas de idade, não sendo observadas concentrações séricas consideráveis até os 2 meses de idade. As concentrações aumentam gradativamente até atingir o nível dos adultos aos 5 meses (JEFFCOTT, 1974; MCGUIRE et al., 1977). Como não foi possível o acompanhamento dos potros por mais tempo, não pôde ser observado o ritmo de elevação dos níveis de imunoglobulinas endógenas. Também não foi observada relação entre os níveis de proteínas plasmáticas totais e globulinas das éguas genitoras (Gráfico 3) e de seus respectivos potros após a ingestão do colostro nesse experimento, uma vez que não houve diferenças significativas entre os níveis plasmáticos dos potros de éguas com níveis mais elevados e as com níveis um pouco mais baixos. Desta forma, faz-se necessário realizar um novo estudo avaliando também a qualidade do colostro.

Gráfico 3 - Níveis de proteína total, albumina e globulina (mg/dl) das éguas prenhes (1 a 10) 


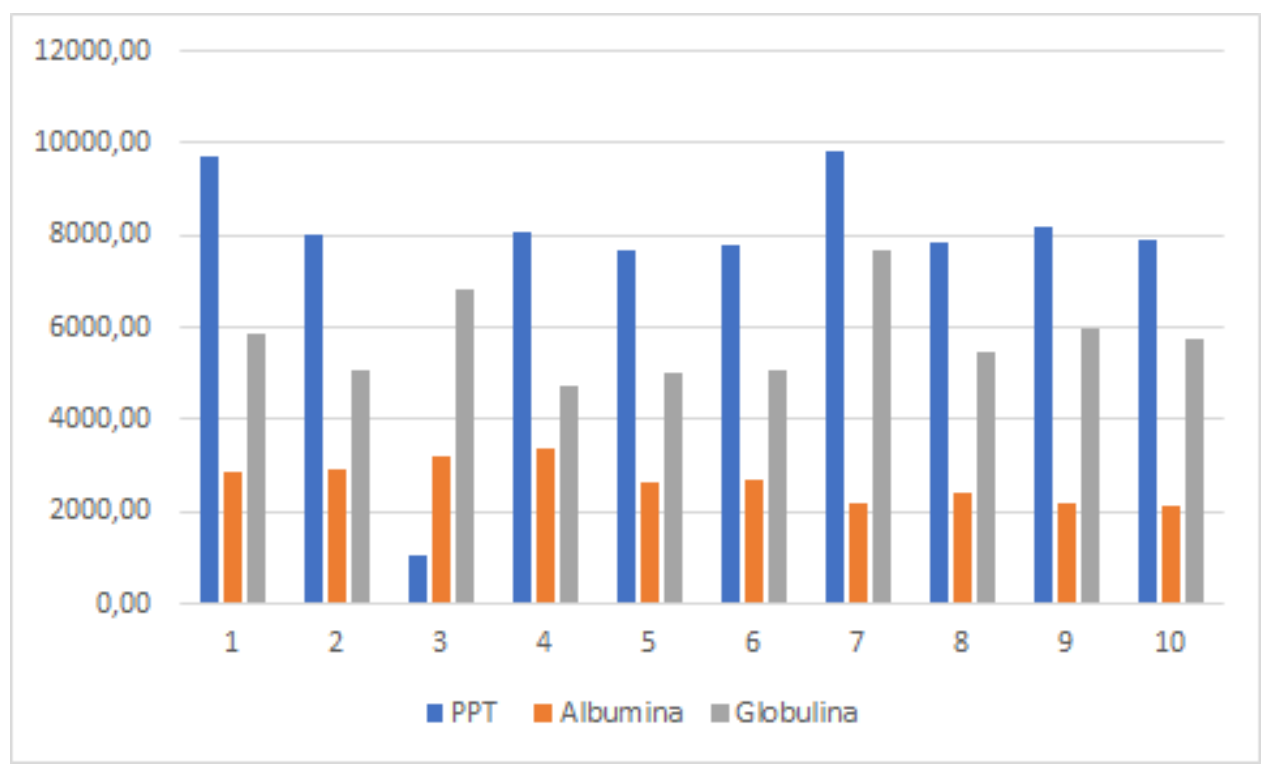

Fonte: arquivo próprio

\section{CONSIDERAÇÕES FINAIS}

Diante dos dados apresentados, foi possível verificar que os animais estudados obtiveram transferência de imunidade passiva efetiva, o que indica que a oferta do colostro em tempo hábil corrobora para um melhor aproveitamento do neonato, indicando também que este foi suficiente para estabelecer níveis iniciais de imunidade, porém, não se prolongaram, pois aos 30 dias de idade os animais apresentaram novo aumento nos níveis de imunoglobulinas indicando início da produção de imunidade inata, o que pode estar relacionado com a qualidade do colostro.

Desta forma, faz-se necessário a realização de mais estudos que definam a relação entre os níveis plasmáticos de imunoglobulinas maternas e a taxa de transferência dessas imunoglobulinas para o colostro, conferindo sua qualidade, além de dosar a quantidade de imunoglobulinas que efetivamente chegam ao neonato após a ingestão do colostro. Assim seria possível determinar a relação entre as imunoglobulinas maternas e do neonato com maior precisão. 


\section{REFERÊNCIAS}

ACWORTH, N. R. J. The healthy neonatal foal: routine examinations and preventative medicine. Equine Veterinary Education, 6, 45-49, 2003.

BAIRD, A. N., PUGH, D. G., RUPP, G. P., SHULL, J. W. \& FIELD, R. W. Detection of immunoglobulin $\mathrm{G}$ in the neonate. Journal of Equine Veterinary Science, 7(3), 124-129, 1987.

BLACKMER, J. M., SELLON, D. C. \& HINES, M. T.). Failure of passive transfer. In B. P. Smith (Ed.), Large Animal Internal Medicine (3rd ed., pp. 1592-1595). St Louis: Elsevier Mosby, 2002.

Bobos, S., Jovanovic-panic, L., Trailovic, D., Pajic, M., Rasic, Z. \& Radinovic, M. (2013). Concentration of total immunoglobulins in blood and milk of periparturient mares and their transfer to foals via colostrum. Bulgarian Journal of Agricultural Science, 19(6), 1431-1436.

BOYD, J.W. The relationship between serum immunoglobulin deficiency and disease in calves: a farm survey. Veterinary Record, London, 90 (23): 645-49, jun. 1972.

CHUCRI, T. M., MONTEIRO, J. M., Lima, A. R., SALVADORI, M. L. B., JUNIOR, J. R. K. \& MIGLINO, $M$. A. A review of immune transfer by the placenta. Journal of Reproductive Immunology, 87(1-2), 14-20, 2010.

COHEN, N. D. Causes of and farm management factors associated with disease and death in foals. Journal of the American Veterinary Medical Association, 1994.

COOK, A.G. Interpretation of the detection of antibodies to Sarcocistis neurona in the serum and CSF of young horses. Blacksburg, 2001. Masters - Faculty of Virginia Polytechnic Institute and State University.

CRISMAN, M. V. \& SCARRATT, W. K. Immunodeficiency disorders in horses. The Veterinary Clinics of North America. Equine Practice, 24(2), 299-310, 2008.

FENGER, C. K. Doenças dos potros, p. 803-839. In: Reed, S. M. \& Bayly, W. M. (ed.) Medicina interna equina. Guanabara Koogan, Rio de Janeiro, 2000.

GIGUÈRE, S. \& POLKES, A. C. Immunologic disorders in neonatal foals. Veterinary Clinics of North America: Equine Practice, 21(2), 241-272, 2005.

GOMES, D. C., Pavarini, S. P. \& Pedroso, P. M. O. Alterações patológicas em potros infectados por Actinobacillus equuli subsp. Haemolyticus. Ciência Rural, 2010.

HAFEZ, E. S. E.; HAFEZ, B. Reprodução animal. 7. ed. São Paulo: Manole, 2004. 513 p. 
JEFFCOTT, L. B. Some practical aspects of the transfer of passive immunity to newborn foals. Equine Veterinary Journal,6:109-115, 1974

JEFFCOTT, L.B. The transfer of passive immunity to the foal and its relation to immune status after birth. Journal of Reproduction Fertility, Oxford, 23: 727- 733, 1975.

KOHN, C. W., KNIGHT, D., HUESTON, W., JACOBS, R. \& REED, S. M. Colostral and serum IgG, IgA, and IgM concentrations in Standardbred mares and their foals at parturition. Journal of the American Veterinary Medical Association, 195(1), 64-8., 1989.

KOTERBA, A. M., BREWER, B., DRUMMOND, W. H. Prevention and control of infection. Vet Clin North Am (Equine Pact), 1985.

KOTERBA, A.M., DRUMOND, W. H. \& KOSCH, P. C. Equine clinical neonatology. Philadelphia: Lea \& Febiger. 846p, 1990.

LAVOIE, J. P., SPENSLEY, M. S., SMITH, B. P. \& MIHALYI, J. Colostral volume and immunoglobulin $\mathbf{G}$ and $\mathbf{M}$ determinations in mares. American Journal of Veterinary Research, 50(4), 466-70, 1989.

LEBLANC, M. M., MCLAURIN, B. I. \& BOSWELL, R. Relationships among serum immunoglobulin concentration in foals, colostral specific gravity, and colostral immunoglobulin concentration. Journal of the American Veterinary Medical Association, 189(1), 57-60, 1986.

LEBLANC, M. M., TRAN, T., BALDWIN, J. L. \& PRITCHARD, E. L. Factors that influence passive transfer of immunoglobulins in foals. Journal of the American Veterinary Medical Association, 200(2), 179-83, 1992.

LeBLANC, M.M.. Immunologic considerations. In: . Equine Clinical Neonatology. Philadelphia: Lea and Febiger, 1990. p.275-294.

LEBLANC, M.M., MCLAURIN, B.I., BOSWELL, R. Relationship among serum immunoglobulin concentration in foals, colostral specific gravity and colostral immunoglobulin concentration. Journal of American Veterinary Medical Association, Chicago, 189 (1) : jul. 1986.

LIMA, R.A.S.; SHIROTA, R.; BARROS, G.S.C. Estudo do complexo do agronegócio cavalo. Piracicaba: ESALQ/USP, 2006. 250p.

LINS, L. A., RIBAS, L. M. \& NOGUEIRA, C. E. W. Principais agentes isolados do trato respiratório de potros Puro Sangue Inglês, do nascimento ao sexto mês de vida, na região de BagéRS Dados preliminares. Anais XVI Congresso de Iniciação Cientifica, 27-29 nov., Pelotas, RS, 2007.

MAPA. Ministério da Agricultura, Pecuária e Abastecimento. 2016. Revisão do Estudo do Complexo do Agronegócio Cavalo. Disponível em: 
<http://www.agricultura.gov.br/assuntos/camar as-setoriaistematicas/documentos/camarassetoriais/equideocultura/anosanteriores/revisao-doestudo-do-complexo-doagronegocio-do-cavalo/view>. Acesso em: 20 abr. 2019.

MCGUIRE, T. C. \& CRAWFORD, T. B. Passive immunity in the foal: measurement of immunoglobulin classes and specific antibody. American Journal of Veterinary Research, 34(10), 1299-1303, 1973.

MCGUIRE, T. C. et al. Failure of colostral immunoglobulin transfer as an explanation for most infections and deaths of neonatal foals. J Am Vet Med Assoc 170:1302-1304, 1977.

MCGUIRE T. C, POPPIE MJ \& BANKS, KL. Hypogammaglobulinemia predisposing to infections in foals. Journal of American Veterinary Medical Association, 166: 1138-1140, 1975.

MUNROE, G. \& STONEHAM, S. The foal. In G. A. Munroe \& J. S. Weese (Eds.), Equine Clinical Medicine, Surgery and Reproduction (pp. 966-994). London: Manson Publishing, 2011.

NATH, L. C., ANDERSON, G. A., SAVAGE, C. J. \& MCKINNON, A. O. Use of stored equine colostrum for the treatment of foals perceived to be at risk for failure of transfer of passive immunity. Journal of the American Veterinary Medical Association, 236(10),1085-1090, 2010.

PERRYMAN, L. E. \& MCGUIRE, T. C. Evaluation for immune system failures in horses and ponies. Journal of the American Veterinary Medical Association, 176(12), 1374- 1377, 1980.

PLATT, H. Septicemia in the foal. British Veterinary Journal, London, 129: 221-29, 1973.

RADOSTITS, O. M., Gay C. C., BLOOD, D. C. \& HINCHCLIFF, K. W. Clinica veterinária: um tratado de doenças dos bovinos, ovinos, suínos, caprinos e eqüinos. 9ạ ed. Guanabara Koogan, Rio de Janeiro. 136p, 2002.

RAIDAL, S. L., MCTAGGART, C. \& PENHALE, J. Effect of withholding macromolecules on the duration of intestinal permeability to colostral IgG in foals. Australian Veterinary Journal, 83(1-2), 78-81, 2005.

REED, S. M; BAYLY, W. M.; SELLON, D. C. Equine Internal Medicine, 2 ed. St. Louis. Saunders, 2004.

SARDINHA, A. B. et al. A Importância Do Colostro Em Neonatos Equinos. Revista Científica Intellectus, [s. I.], n. 39, p. 21-38, 2017.Disponível em: $<$ http://search.ebscohost.com/login.aspx?direct=true\&db=asn\&AN=124925979\&lang=ptbr\&site=ehost-live >. Acesso em: 27 abr. 2019.

SCOTONI, C. M. M.; MACHADO, N, R. Transferência de imunidade passiva em equinos: comportamento imunológico do recém nascido. An. Esc. Super. Agric. Luiz de Queiroz, Piracicaba , v. 48, p. 109-126, $1991 \quad$. $\quad$ Disponible en <http://www.scielo.br/scielo.php?script=sci_arttext\&pid=S0071- 
12761991000100007\&Ing=es\&nrm=iso>. accedido el $29 \quad$ abr. 2019 . http://dx.doi.org/10.1590/S0071-12761991000100007.

SELLON, D. C., HINES, M. T. \& JOHNSON, J. R. Immunologic disorders. In B. P. Smith (Ed.), Large Animal Internal Medicine (4th ed., pp. 1665-1670). St Louis: Mosby, Elsevier, 2009.

SELLON, D. C. Secondary immunodeficiencies of horses. The Veterinary Clinics of North America. Equine Practice, 16(1), 117-130, 2000.

SMITH, B. P. Medicina Interna de Grandes Animais, 3 ed. Barueri. Manole, 2002.

STONEHAM, S. J. Failure of passive transfer of colostral immunity in the foal. Equine Veterinary Education, 3, 43-44, 1991.

TIZARD I. R. Imunologia veterinária, 6 ed. São Paulo. Roca, 2002.

$532 p$.

TIZARD, I. R. Veterinary Immunology: An Introduction (7th ed.). Philadelphia: Saunders, 2004.

TYLER-MCGOWAN, C., HODGSON, J. \& HODGSON, D. Failure of passive transfer in foals: incidence and outcome on four studs in New South Wales. Australian Veterinary Journal, 75, $56-59,1997$.

TOWSEND, H.G.G., TABEL, H., BRISTOL, F.M. Induction of parturition in mares: effect on passive transfer of immunity to foals. Journal of American Veterinary Medical Association, Chicago, 182 (3) : 255-57, fev. 1983.

UNANIAN, M. M.; SILVA, A.E.D.F.; PEREIRA, A.C. U54c. Colostro de égua no aleitamento artificial. São Carlos: EMBRAPA - CPPSE, 1994. 21 p. (EMBRAPA-CPPSE. Circular Técnica, 08)

VILAR, A.L.T.; COSTA, R.G.; SOUZA, P.M. et al. Efeito da ordem de parição e do período de ordenha na produção e composes do colostro e do leite de transição de cabras. Saanem. Revista Brasileira de Zootecnia, v.37, n.9, p.1674-1678, 2008. 